3 Waschki B, Kirsten A, Holz O, et al. Physical activity is the strongest predictor of all-cause mortality in patients with COPD: a prospective cohort study. Chest 2011; 140: 331-342.

4 Watz H, Pitta F, Rochester CL, et al. An official European Respiratory Society statement on physical activity in COPD. Eur Respir J 2014; 44: 1521-1537.

5 Garfield BE, Canavan JL, Smith CJ, et al. Stanford Seven-Day Physical Activity Recall questionnaire in COPD. Eur Respir J 2012; 40: 356-362.

6 Williams K, Frei A, Vetsch A, et al. Patient-reported physical activity questionnaires: a systematic review of content and format. Health Qual Life Outcomes 2012; 10: 28.

7 Leidy NK. Functional status and the forward progress of merry-go-rounds: toward a coherent analytical framework. Nurs Res 1994; 43: 196-202.

8 Kocks JW, Asijee GM, Tsiligianni IG, et al. Functional status measurement in COPD: a review of available methods and their feasibility in primary care. Prim Care Respir J 2011; 20: 269-275.

9 Gimeno-Santos E, Raste Y, Demeyer H, et al. The PROactive instruments to measure physical activity in patients with chronic obstructive pulmonary disease. Eur Respir J 2015; 46: 988-1000.

10 Rabinovich RA, Louvaris Z, Raste Y, et al. Validity of physical activity monitors during daily life in patients with COPD. Eur Respir J 2013; 42: 1205-1215.

11 Van Remoortel H, Raste Y, Louvaris Z, et al. Validity of six activity monitors in chronic obstructive pulmonary disease: a comparison with indirect calorimetry. PLoS One 2012; 7: e39198.

12 Demeyer H, Burtin C, van Remoortel H, et al. Standardizing the analysis of physical activity in patients with COPD following a pulmonary rehabilitation program. Chest 2014; 146: 318-327.

13 Deeks JJ, Altman DG. Diagnostic tests 4: likelihood ratios. BMJ 2004; 329: 168-169.

14 Dobbels F, de Jong C, Drost E, et al. The PROactive innovative conceptual framework on physical activity. Eur Respir J 2014; 44: 1223-1233.

15 DePew ZS, Garofoli AC, Novotny PJ, et al. Screening for severe physical inactivity in chronic obstructive pulmonary disease: the value of simple measures and the validation of two physical activity questionnaires. Chron Respir Dis 2013; 10: 19-27.

16 van Gestel AJ, Clarenbach CF, Stowhas AC, et al. Predicting daily physical activity in patients with chronic obstructive pulmonary disease. PLoS One 2012; 7: e48081.

\title{
Urokinase plasminogen activator receptor polymorphisms and airway remodelling in asthma
}

\section{To the Editor:}

In the past decade, several asthma genes have been identified [1]; however, the key challenge is to determine how these genetic changes contribute to the underlying lung biology. We identified the urokinase plasminogen activator receptor (PLAUR) as an asthma susceptibility gene by positional cloning [2]. We showed that the same single nucleotide polymorphisms (SNPs) were associated with soluble PLAUR levels in blood, airway hyperresponsiveness (AHR) and accelerated lung function decline in asthma; a clinical feature linked to airway wall remodelling [2]. Therefore, we hypothesised that PLAUR may contribute to structural changes in asthma via increased levels of the membrane bound or soluble receptor. We subsequently showed that PLAUR levels were elevated in the airway epithelium of asthma patients and that PLAUR has a role in epithelial repair responses [3]. The aim of the current study was to 1) test for association between PLAUR SNPs and markers of airway remodelling using bronchial biopsies from asthma patients; and 2) test for association between SNPs and staining for PLAUR in airway tissue.

This study utilised bronchial biopsy samples from 137 asthma patients. These subjects were previously recruited in the northern Netherlands and re-examined during 2002-2006 [4]. Lung function testing and AMP provocation tests were performed and subjects were considered to have AHR when an AMP concentration of $<320 \mathrm{mg} \cdot \mathrm{mL}^{-1}$ caused a $20 \%$ fall in forced expiratory volume in $1 \mathrm{~s}(\mathrm{FEV} 1)$. DNA samples were available in all 137 subjects. Bronchoscopy, collection and processing of the bronchial biopsies were performed as previously described, including quantification of remodelling markers [4]. Quantification was performed on the largest of three biopsy sections taken. Clinical characteristics of the asthma patients investigated and details on genotyping and immunohistochemistry are available on request. The study was approved by the University Medical Center Groningen ethics committee and participants signed informed consent forms.

Bronchial biopsies were characterised for: 1) basement membrane thickness $(\mu \mathrm{m})$; 2) sub-epithelial vasculature (number of $\mathrm{CD} 1^{+}$vessels per $0.1 \mathrm{~mm}^{2}$ of submucosa); 3 ) percentage intact epithelium; 4) basal 
epithelial proliferation (percentage of $\mathrm{Ki}^{+} 7^{+}$cells in basal epithelium); 5) collagen III deposition (\% positive per $200 \mu \mathrm{m}$-area under basement membrane); 6) lung function (FEV1 \% predicted and FEV1/vital capacity pre- and post-bronchodilator); 7) AHR (provocative concentration causing a $20 \%$ fall in FEV1 AMP $<320 \mathrm{mg} \cdot \mathrm{mL}^{-1}$ ); and 8) PLAUR (immunohistochemistry) epithelial expression (low/high expression).

Basement membrane thickness was calculated by dividing surface area by length $(\mu \mathrm{m})$, based on computer-assisted measurements. The number of $\mathrm{CD}^{+} 1^{+}$(DAKO, Cambridgeshire, UK) vessels in the submucosal area was counted in the whole section (excluding areas of epithelium, muscle and mucus glands), therefore measuring the number of vessels per area $\left(0.1 \mathrm{~mm}^{2}\right)$. Epithelial layer integrity was assessed on haematoxylin and eosin stained biopsy sections and expressed as the percentage of basement membrane covered with normal, intact epithelium. Reproducibility of the measurements was confirmed by a single observer performing repeated measurements in $10 \%$ of all cases.

22 SNPs spanning PLAUR were genotyped [2] (data available on request from the authors) and allele frequencies did not deviate from Hardy-Weinberg equilibrium $(\mathrm{p}<0.05)$. There was some redundancy in the genotyping with $\mathrm{r}^{2}$ values $>0.8$ for: $\mathrm{rs} 4803648 / \mathrm{rs} 4802189 / \mathrm{rs} 4251938, \mathrm{rs} 2356338 / \mathrm{rs} 4251831$ and rs344780/rs344781.

Normalisation of variable distribution was performed by natural logarithm transformation. Multiple linear regression models were used to test for associations of PLAUR SNPs with all continuous outcomes and logistic regression for AHR. As the number of subjects with the homozygote mutant genotype was low in the two subgroups $(\mathrm{n}<10)$, only dominant (heterozygotes and homozygotes mutants pooled versus wild types) models were used, adjusted for age, sex, smoking and inhaled corticosteroid (ICS) use. A simple linear and logistic regression model was used to assess associations between epithelial PLAUR expression and clinical and remodelling parameters, smoking and ICS use. Associations of epithelial PLAUR expression with $\mathrm{p}<0.05$ in univariate analyses were also tested in multivariate models. Genetic analysis was performed separately in never- and ever- (current and ex-) smokers. p-values of $<0.05$ were considered statistically significant $(2$-sided tests). As there was a priori evidence of an association between the SNPs chosen for study and asthma and lung function related phenotypes [2,5], we have not corrected for the number of SNPs and tests completed. Importantly, the outcome variables in our analyses are not independent (e.g. for basement membrane thickness and percentage intact epithelium, the correlation coefficient is $-0.294 ; \mathrm{p}<0.001$ ) and several SNPs are in linkage disequilibrium making, for example, Bonferroni correction over conservative. This approach is in line with other similar studies [6]. We therefore report associations for p-values of $<0.001-0.05$.

11 of the 22 SNPs analysed showed association with one or more outcomes including: AHR, basal epithelial proliferation, basement membrane thickness and collagen III deposition (figure 1a). Seven of these 11 SNPs had previously been associated with asthma and four with lung function decline in asthma (figure 1a). Of interest, eight of these 11 SNPs showed an association with basal epithelial proliferation (Ki67), identifying a potential role for PLAUR in epithelial homeostasis as suggested previously [3]. This observation is in line with findings showing that epithelial cells overexpressing PLAUR have altered proliferation in vitro [7]. In addition, soluble cleaved PLAUR is elevated in induced sputum [8] and lavage fluid following allergen challenge in asthma patients [9].

PLAUR protein expression in biopsies was prominent in the epithelium as anticipated [3]. Staining was apical suggesting increased soluble PLAUR; however, we cannot exclude antibody or sample driven differences when we compare with previous staining [3] using a different, now unavailable antibody (figure $1 \mathrm{~b}-\mathrm{e})$. We identified individuals with high $(\mathrm{n}=50)$ and low $(\mathrm{n}=41)$ epithelial staining. Of interest, ICS use was associated with lower PLAUR levels in the epithelium (adjusted OR $=0.301,95 \%$ CI 0.122 0.745; $\mathrm{p}=0.009$ ), showing ICS responsiveness as suggested previously [9]. We tested for association between PLAUR staining intensity and remodelling outcomes and showed that strong epithelial PLAUR staining was associated with reduced basal epithelial proliferation ( $37 \%$ decrease, adjusted $p=0.010$, figure 1f). These data identify that epithelial PLAUR levels relate to basal epithelial proliferation in vivo. However, we did not identify an association between PLAUR SNPs and the epithelial PLAUR staining, potentially due to insufficient power (data not shown). While a strength of our study is measurement of PLAUR expression in lung tissue, this was limited by it being a categorical rather than a quantitative measurement as samples for Western blotting were unavailable. Previously, we demonstrated that several of these $5^{\prime}$ region SNPs (rs2356338, rs4493171, rs1994417, rs346043) were associated with serum/plasma PLAUR levels [2].

In the ENCODE dataset [10], SNPs identified in figure 1a as associated with airway remodelling measures, were enriched for DNase sites in tracheal epithelial cells (11.1 fold enrichment; $\mathrm{p}=0.013$ ) and enhancer sites (e.g. in K562 cells, 17.7 fold enrichment; p=0.0006). However, analysis of a lung expression quantitative trait loci dataset did identify a role for PLAUR SNPs as determinants of PLAUR mRNA levels at the $10 \%$ false discovery rate level in total lung [11]. This however does not necessarily imply that the SNPs are unimportant in specific cells, e.g. epithelial cells. 


\begin{tabular}{|c|c|c|c|c|c|}
\hline \multirow[t]{2}{*}{ SNP } & \multirow[t]{2}{*}{ Outcome } & \multicolumn{2}{|c|}{ This study } & \multicolumn{2}{|c|}{ Previous study [2] } \\
\hline & & $\beta$ & $\overline{p-v a l u e}$ & Asthma & Decline \\
\hline $\begin{array}{l}\text { rs4803648-A } \\
\text { 3'UTR }\end{array}$ & $\begin{array}{c}\text { AHR lodds ratio estimates) } \\
\text { Basal epithelial proliferation Ki67+ } \\
\text { Collagen III deposition }\end{array}$ & $\begin{array}{l}0.448 \\
0.482 \\
5.223\end{array}$ & $\begin{array}{l}0.044 \\
0.001 \\
0.037\end{array}$ & Risk & Accelerated \\
\hline $\begin{array}{l}\text { rs4802189-A } \\
\text { 3'UTR }\end{array}$ & $\begin{array}{l}\text { AHR lodds ratio estimates) } \\
\text { Basement membrane } \\
\text { Basal epithelial proliferation Ki67+ }\end{array}$ & $\begin{array}{c}0.406 \\
-0.743 \\
0.449\end{array}$ & $\begin{array}{l}0.034 \\
0.010 \\
0.005\end{array}$ & Risk & Accelerated \\
\hline $\begin{array}{l}\text { rs4251938-G } \\
\text { 3'UTR/intron }\end{array}$ & $\begin{array}{l}\text { Basement membrane thickness } \\
\text { Basal epithelial proliferation Ki67+ }\end{array}$ & $\begin{array}{l}-0.679 \\
0.592\end{array}$ & $\begin{array}{l}0.020 \\
\leftarrow 0.001\end{array}$ & Risk & Accelerated \\
\hline $\begin{array}{l}\text { rs2302524-C } \\
\text { Lys220/175Arg }\end{array}$ & Basal epithelial proliferation Ki67+ & 0.300 & 0.049 & Risk & Accelerated \\
\hline $\begin{array}{l}\text { rs4251864-C } \\
\text { Intron } 3\end{array}$ & AHR (odds ratio estimates) & 3.034 & 0.019 & No & No \\
\hline $\begin{array}{l}\text { rs4251831-C } \\
\text { Intron } 1\end{array}$ & Basal epithelial proliferation Ki67+ & -0.365 & 0.009 & No & ND \\
\hline $\begin{array}{l}\text { rs2356338-T } \\
5^{\prime}-649\end{array}$ & Basal epithelial proliferation Ki67+ & -0.443 & 0.001 & Risk & Accelerated \\
\hline $\begin{array}{l}\text { rs344779-T } \\
5^{\prime}-3665\end{array}$ & Basal epithelial proliferation Ki67+ & 0.383 & 0.006 & No & ND \\
\hline $\begin{array}{l}\text { rs4493171-T } \\
5^{\prime} 10533\end{array}$ & Collagen III deposition & 4.595 & 0.048 & Protect & ND \\
\hline $\begin{array}{l}\text { rs1994417-T } \\
5^{\prime}-13183\end{array}$ & $\begin{array}{l}\% \text { intact epithelium } \\
\text { Collagen III deposition }\end{array}$ & $\begin{array}{l}0.248 \\
5.895\end{array}$ & $\begin{array}{l}0.026 \\
0.011\end{array}$ & No & ND \\
\hline $\begin{array}{l}\text { rs } 346043-C \\
5^{\prime}-20458\end{array}$ & Basal epithelial proliferation Ki67+ & -0.337 & 0.019 & Risk & ND \\
\hline
\end{tabular}
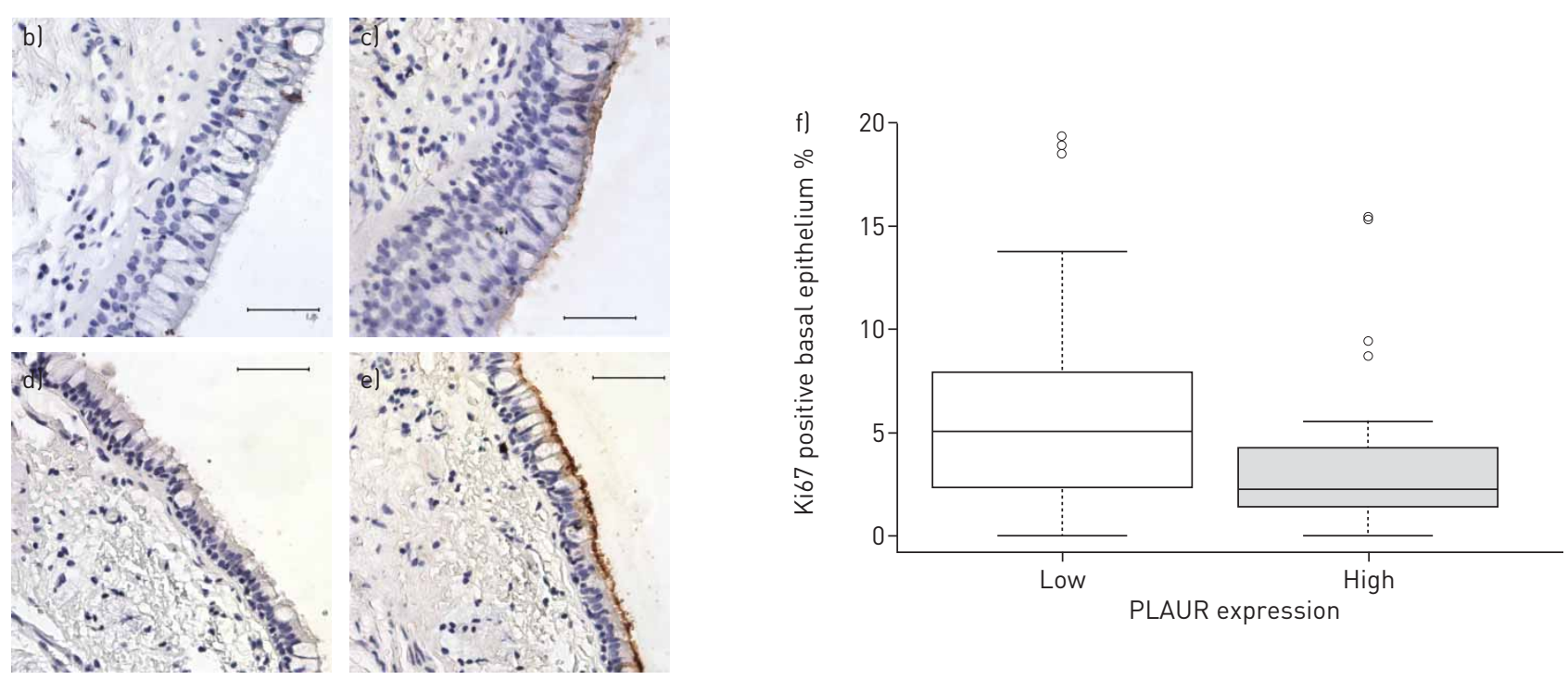

FIGURE 1 Main associations between PLAUR (urokinase plasminogen activator receptor) single nucleotide polymorphisms (SNPs) and markers of airway remodelling, and immunohistochemical analyses of PLAUR protein expression in asthma patient biopsies. a) Genetic associations. All SNP associations are adjusted for age, sex, inhaled corticosteroid use and ever-smoking. Smoking was an identified confounder for this dataset (data not shown). SNP associations with various remodelling outcomes are presented in comparison with previous associations with asthma and/or decline in lung function in asthmatic subjects [2]. Examples of b) isotype control and c) low level PLAUR expression. Examples of d) isotype control and e) high level PLAUR. b-e) Scale bars=50 $\mu \mathrm{m}$. f) Basal epithelial cell proliferation (Ki67) is significantly higher in low ( $\mathrm{n}=41$ ) versus high ( $\mathrm{n}=50$ ) PLAUR categorised biopsies ( $p=0.005$ ). Boxes represent the median and $25-75$ th percentiles and whiskers the minimum and maximum values (excluding outliers, shown as dots). UTR: untranslated region; AHR: airway hyper-responsiveness; ND: not determined.

Cigarette smoke can induce PLAUR expression in the airways and may contribute to the bronchial epithelial phenotype $[12,13]$. Although investigating a possible SNP interaction with smoke exposure would be of interest to this study, we were constrained by limited numbers of smokers (ever-smokers $\mathrm{n}=75$; never-smokers $\mathrm{n}=61$ ). 
PLAUR is a serine protease receptor with many downstream effects including ECM degradation as well as non-plasmin functions, e.g. cell migration and proliferation [14]. The current study provides further indications that PLAUR may be involved in airway remodelling in asthma through alterations in epithelial function, which is, at least in part, driven by genetic polymorphisms. Further investigation into the role of PLAUR in asthma may provide therapeutic opportunities to target airway remodelling in asthma. biopsies of asthma patients http://ow.ly/X5Srl

Despo Ierodiakonou ${ }^{1,2,7}$, Michael A. Portelli ${ }^{3,7}$, Dirkje S. Postma ${ }^{2,4}$, Gerard H. Koppelman ${ }^{2,5}$, Jorrit Gerritsen ${ }^{2,5}$, Nick H.T. ten Hacken ${ }^{2,4}$, Wim Timens ${ }^{2,6}$, H. Marike Boezen ${ }^{1,2}$, Judith M. Vonk ${ }^{1,2}$ and Ian Sayers ${ }^{3}$

${ }^{1}$ Dept of Epidemiology, University of Groningen, University Medical Center Groningen, Groningen, The Netherlands.

${ }^{2}$ Groningen Research Institute for Asthma and COPD, University of Groningen, University Medical Center Groningen, Groningen, The Netherlands. ${ }^{3}$ Division of Respiratory Medicine, University of Nottingham, Queen's Medical Centre, Nottingham, UK. ${ }^{4}$ Dept of Pulmonology, University of Groningen, University Medical Center Groningen, Groningen, The Netherlands. ${ }^{5}$ Dept of Pediatric Pulmonology and Pediatric Allergology, Beatrix Children's Hospital, University of Groningen, University Medical Center Groningen, Groningen, The Netherlands. ${ }^{6}$ Dept of Pathology and Medical Biology, University of Groningen, University Medical Center Groningen, Groningen, The Netherlands. ${ }^{7}$ Both authors contributed equally.

Correspondence: Ian Sayers, Division of Respiratory Medicine, Queen's Medical Centre, University of Nottingham, Nottingham, NG7 2UH, UK. E-mail: ian.sayers@nottingham.ac.uk

Received: Sept 212015 | Accepted after revision: Dec 202015 | First published online: Feb 122016

Support statement: Support came from the University Medical Center Groningen; the Netherlands Asthma Foundation (grant numbers AF 95.09, AF 98.48, AF 3.2.02.51, and AF 3.2.07.015); Asthma UK (grant number 08/017); and the STEPS (Malta) scholarship, financed in part by the European Union, European Social Fund (ESF), under Operational Programme II, Cohesion Policy 2007-2013, Empowering People for More Jobs and a Better Quality of Life. Funding information for this article has been deposited with FundRef.

Conflict of interest: Disclosures can be found alongside the online version of this article at erj.ersjournals.com

\section{References}

1 Portelli MA, Hodge E, Sayers I. Genetic risk factors for the development of allergic disease identified by genome wide association. Clin Exp Allergy 2015; 45: 21-31.

2 Barton SJ, Koppelman GH, Vonk JM, et al. PLAUR polymorphisms are associated with asthma, PLAUR levels, and lung function decline. J Allergy Clin Immunol 2009; 123: 1391-400.

3 Stewart CE, Nijmeh HS, Brightling CE, et al. uPAR regulates bronchial epithelial repair in vitro and is elevated in asthmatic epithelium. Thorax 2012; 67: 477-487.

4 Broekema M, ten Hacken NH, Volbeda F, et al. Airway epithelial changes in smokers but not in ex-smokers with asthma. Am J Respir Crit Care Med 2009; 180: 1170-1178.

5 Stewart CE, Hall IP, Parker SG, et al. PLAUR polymorphisms and lung function in UK smokers. BMC Med Genet 2009; 10: 112.

6 Collins SA, Lucas JS, Inskip HM, et al. HHIP, HDAC4, NCR3 and RARB polymorphisms affect fetal, childhood and adult lung function. Eur Respir J 2013; 41: 756-757.

7 Portelli MA, Siedlinski M, Stewart CE, et al. Genome-wide protein QTL mapping identifies human plasma kallikrein as a post-translational regulator of serum uPAR levels. FASEB J 2014; 28: 923-934.

8 Xiao W, Hsu YP, Ishizaka A, et al. Sputum cathelicidin, urokinase plasminogen activation system components, and cytokines discriminate cystic fibrosis, COPD, and asthma inflammation. Chest 2005; 128: 2316-2326.

9 Brooks AM, Bates ME, Vrtis RF, et al. Urokinase-type plasminogen activator modulates airway eosinophil adhesion in asthma. Am J Respir Cell Mol Biol 2006; 35: 503-511.

10 ENCODE Project Consortium. An integrated encyclopedia of DNA elements in the human genome. Nature 2012; 489: $57-74$.

11 Hao K, Bossé Y, Nickle DC, et al. Lung eQTLs to help reveal the molecular underpinnings of asthma. PLoS Genet 2012; 8: e1003029.

12 Wang Q, Wang Y, Zhang Y, et al. The role of uPAR in epithelial-mesenchymal transition in small airway epithelium of patients with chronic obstructive pulmonary disease. Respir Res 2013; 14 : 67.

13 Portelli MA, Stewart CE, Hall IP, et al. Cigarette smoke and the induction of urokinase plasminogen activator receptor in vivo: selective contribution of isoforms to bronchial epithelial phenotype. Am J Respir Cell Mol Biol 2015; 53: 174-183.

14 Smith HW, Marshall CJ. Regulation of cell signalling by uPAR. Nat Rev Mol Cell Biol 2010; 11: 23-36. 